\title{
Investigation of the Martensitic Transformation in High-Chromium Cast Irons using Microscopy and Microanalysis
}

\author{
B. Hinckley ${ }^{*}$, K. F. Dolman ${ }^{*}$, R. Wuhrer ${ }^{* *}$, K. Moran ${ }^{* * *}$, W. Yeung ${ }^{* * * *}$ and A. Ray ${ }^{* * * * *}$ \\ ${ }^{*}$ Weir Minerals Australia Ltd, Locked Bag 51, Artarmon, NSW 1570, Australia. \\ ${ }^{* *}$ Microstructural Analysis Unit, University of Technology, Sydney, PO Box 123, Broadway, \\ NSW 2007, Australia. \\ ${ }_{* * * * *}^{* *}$ Moran Scientific Pty Ltd, PO Box 651, Goulburn, NSW 2580, Australia. \\ ${ }_{* * * * * *}^{*}$ Department of Physics and Advanced Materials, University of Technology, Sydney. \\ Centre for Built Infrastructure Research, Faculty of Engineering, UTS.
}

High-chromium white cast irons are used extensively in the mining, minerals processing, earthmoving and manufacturing industries in applications requiring resistance to abrasive and erosive wear [1-3]. White cast irons owe their excellent wear properties primarily to the presence of a significant proportion of hard carbide phases in their microstructures. In order to achieve optimum abrasion resistance for many applications, high-chromium cast irons are subjected to an age-hardening heat treatment during which secondary carbide precipitation occurs which in turn promotes transformation of the relatively soft austenitic matrix to the harder martensite phase upon cooling to room temperature [1-4]. The transformation of the matrix to martensite is important to the wear resistance of white cast irons since the relatively hard martensite offers support and protection to the carbide phase from abrasive particles during service [4].

The martensitic reaction is temperature-dependent. Upon cooling, the transformation of austenite to martensite commences at the martensite start temperature $\left(\mathrm{M}_{\mathrm{s}}\right)$ and continues until the reaction is complete at the martensite finish temperature $\left(\mathrm{M}_{\mathrm{f}}\right)$. When the $\mathrm{M}_{\mathrm{f}}$ is below room temperature, as is often the case in abrasion-resistant cast irons, a proportion of the relatively soft untransformed austenite will be retained in some areas throughout the matrix [5].

The $\mathrm{M}_{\mathrm{s}}$ and $\mathrm{M}_{\mathrm{f}}$ temperatures are a function of alloy matrix composition. Most alloying elements have a suppressing effect on the martensite formation temperatures. In low-alloy steels, the $\mathrm{M}_{\mathrm{s}}$ temperature can be estimated using established empirical relationships, such as Andrew's equation [5] modified by Kung \& Rayment [6], which can be written as follows:

$$
\mathrm{M}_{\mathrm{s}}\left({ }^{\circ} \mathrm{C}\right)=539-423 \mathrm{C}-30.4 \mathrm{Mn}-17.7 \mathrm{Ni}-12.1 \mathrm{Cr}-7.5 \mathrm{Mo}+10 \mathrm{Co}-7.5 \mathrm{Si}
$$

where $\mathrm{C}, \mathrm{Mn}, \mathrm{Ni}, \mathrm{Cr}, \mathrm{Mo}, \mathrm{Co} \& \mathrm{Si}$ represent the compositions of the elements. Andrew's equation is a well-established relationship for estimating the $\mathrm{M}_{\mathrm{s}}$ temperature of low alloy steels. However, it is generally considered that Andrew's equation does not quantitatively apply to the bulk composition of high-chromium cast irons.

The microstructures of a high-chromium cast iron containing $25 \mathrm{Cr}-3 \mathrm{C}$ are shown in Fig. 1-3. The as-cast microstructure contains a predominantly austenitic matrix due to its high alloy content (Fig. 1a). However, thin bands of martensite can be observed surrounding the carbide phase (Fig. 1b\&3b). The presence of these martensitic bands was attributed to the depletion of certain elements, such as carbon and chromium, from the regions of the matrix directly adjacent to the carbide phase leading to a localised increase in the $\mathrm{M}_{\mathrm{s}}$ temperature.

The solution treated microstructure is shown in the micrographs of Fig. 2. During solution treatment at elevated temperature, some homogenisation occurs so that the alloy depleted regions 
have their compositions largely restored. Consequently, upon cooling, the entire austenitic matrix is retained since there are no longer any depleted regions (Fig. 2).

An age-hardened high-chromium cast iron is shown in Fig. 3. Secondary carbides precipitate from the matrix at the aging temperature, leaving the entire matrix depleted with respect to carbon and chromium. As indicated by Andrew's equation [5], this depleted matrix has a higher $\mathrm{M}_{\mathrm{s}}$, so that a substantial amount of martensite forms upon cooling to room temperature.

a.

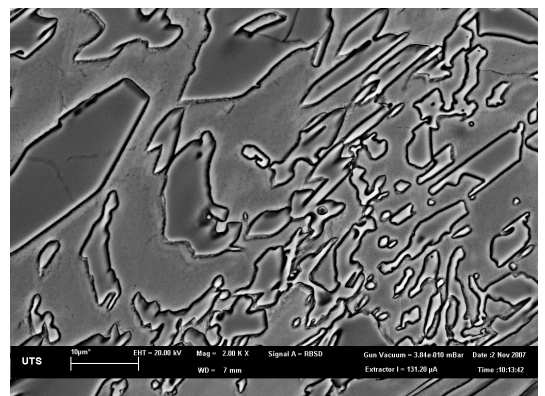

b.

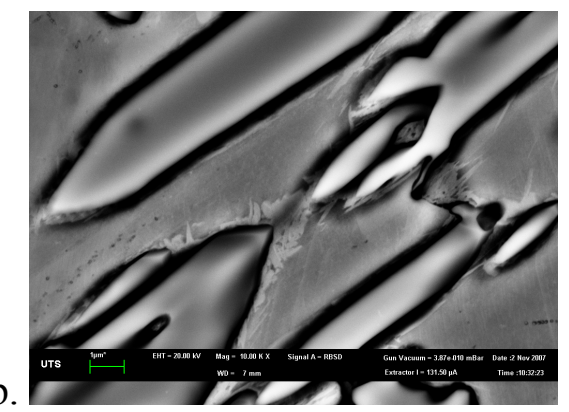

Fig. 1. BSE image of a Fe-25Cr-3C alloy microstructure in the as-cast condition.

a.
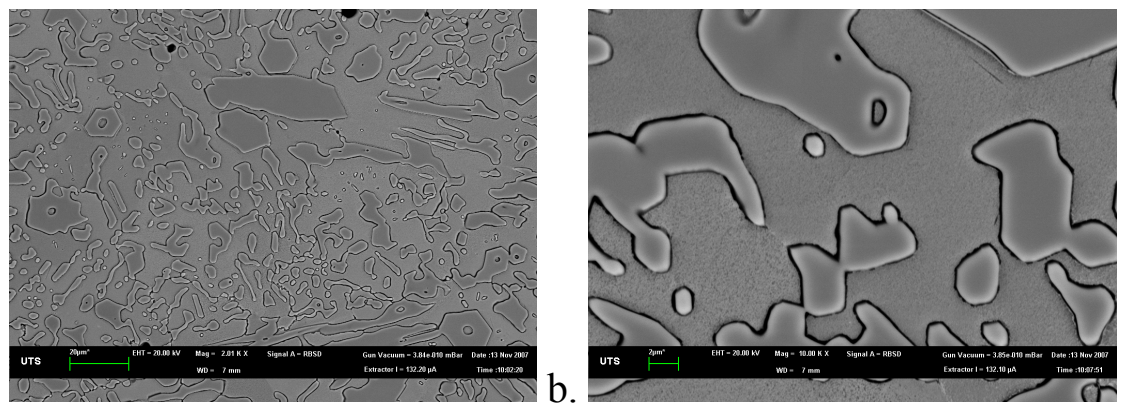

Fig. 2. BSE image of a Fe-25Cr-3C alloy microstructure in a solution treated condition.

a.
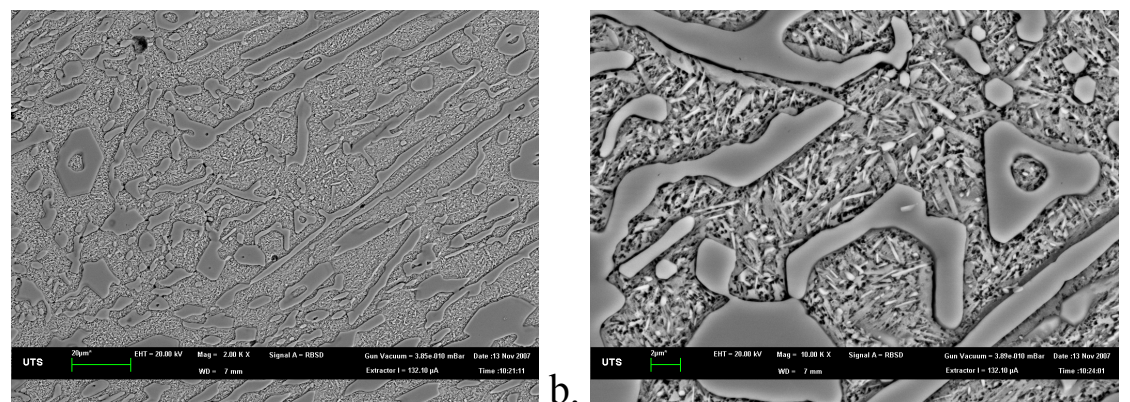

Fig. 3. BSE image of a Fe-25Cr-3C alloy microstructure in age-hardened condition.

This research work examines the effect of various heat treatments on the martensitic transformation in a high-chromium cast iron containing $25 \mathrm{Cr}-3 \mathrm{C}$. The transformation of austenite to martensite was studied using dilatometry and the resultant microstructures examined using scanning electron microscopy. The effect of heat treatments on the martensite reaction was explained with reference to their effect on the composition of the matrix. The changes in the matrix composition were quantified using SEM-WDS microanalysis and the validity of Andrew's equation was evaluated for the main elements in the matrix, rather than bulk chemistry.

[1] Tabrett, C.P.and Sare, I.R., Scripta Mater., Vol. 38 (1998) pp1747-1753.

[2] Llewellyn, R.J. et al., Wear, Vol. 256, Issue 6 (2004) pp592-599.

[3] Hinckley, B et al., Materials Forum, Vol. 32 (2008) pp. 55-71.

[4] Tabrett, C.P. et al., International Metals Reviews, Vol. 41 (1996) No. 2, pp59-80.

[5] Andrews, K.W., Journal of Iron \& Steel Institute, Vol 203 (1965) pp721-727.

[6] Kung, C.Y. and Rayment, J.J., Metallurgical Transactions A, Vol. 13 (1982) pp328-331. 